\title{
Influence of nitrogen pre-implantation on deuterium retention in tungsten
}

\author{
L. Gao ${ }^{1,2}$, W. Jacob ${ }^{* 1}$, P. Wang ${ }^{1}$, U. von Toussaint ${ }^{1}$ and A. Manhard ${ }^{1}$ \\ ${ }^{1}$ Max-Planck-Institut für Plasmaphysik, EURATOM Association, Boltzmannstr. 2, 85748 Garching, Germany \\ ${ }^{2}$ Institute of Plasma Physics, Chinese Academy of Sciences, Shushanhu Rd. 350, 230031 Hefei, China
}

\begin{abstract}
:
The influence of nitrogen (N) pre-implantation on the deuterium (D) retention in tungsten (W) at different temperatures was investigated. Bulk W samples were exposed to D plasma with a fluence of $1 \times 10^{24} \mathrm{D} / \mathrm{m}^{2}$ with or without nitrogen pre-implantation at $300 \mathrm{~K}$ and $500 \mathrm{~K}$, respectively. Nuclear reaction analysis was applied for the determination of $\mathrm{N}$ content and $\mathrm{D}$ retention in the near surface. Optical microscopy was used to investigate the surface modification by blistering after implantation. It is shown that, the $\mathrm{W}: \mathrm{N}$ layers formed during the $\mathrm{N}$ preimplantation play very different roles on $\mathrm{D}$ retention and blistering in the samples at different temperatures. At $500 \mathrm{~K}$, the $\mathrm{W}: \mathrm{N}$ layer seems to enhance $\mathrm{D}$ diffusion into the bulk by suppressing D loss from the surface, which results in a much higher D concentration in the bulk and larger blisters than without $\mathrm{N}$ pre-implantation. At $300 \mathrm{~K}$, the effect of this layer is much less pronounced than that at $500 \mathrm{~K}$.
\end{abstract}

Key words: Tungsten, Nitrogen pre-implantation, Deuterium retention, Blister

PACS: 52.40.Hf, 79.20.Rf, 25.55.-e, 28.52.Fa

$\begin{array}{ll}\begin{array}{l}\text { Published in: } \\ \text { doi: }\end{array} & \begin{array}{l}\text { Physica Scripta T159 (2014) 014023 (5pp). } \\ \text { 10.1088/0031-8949/2014/T159/014023 }\end{array} \\ \text { Submitted: } & 10.05 .2013 \\ \text { Accepted: } & 11.07 .2013 \\ \text { Available online: } & 01.04 .2014\end{array}$

\footnotetext{
${ }^{*}$ Corresponding author. Fax: +49-3299-1504, Tel: +49-3299-2618.

E-mail address: wolfgang.jacob@ipp.mpg.de
} 


\section{Introduction}

For fusion devices with a full-tungsten (W) divertor, such as ASDEX Upgrade (AUG) and JET, it is necessary to seed impurities into the edge plasma to lower the power flux to the outer divertor target. Recent experiments have shown that nitrogen $(\mathrm{N})$ seeding can not only efficiently cool the edge plasma but also improve the overall plasma performance [1-3]. But so far, little is known about the plasma-surface interaction of deuterium (D) with $\mathrm{N}$-implanted W surfaces.

In the present contribution, bulk $\mathrm{W}$ samples are implanted with $\mathrm{D}$ plasma with a fluence of $1 \times 10^{24} \mathrm{D} / \mathrm{m}^{2}$ at temperatures of $300 \mathrm{~K}$ and $500 \mathrm{~K}$, respectively, with or without $\mathrm{N}$ preimplantation. The $\mathrm{N}$ content, $\mathrm{D}$ depth distribution and the surface blistering behavior after implantation are compared among these samples.

\section{Experimental details}

All tungsten specimens in the present work were produced by PLANSEE from one single manufacturing batch, which had a purity of 99.97 wt. \%. After being hot-rolled into a sheet of $0.8 \mathrm{~mm}$ thickness, the tungsten was cut into pieces with the dimensions $12 \times 15 \times 0.8 \mathrm{~mm}^{3}$ by the manufacturer. All the bulk W samples were mechanically polished to a mirror-like surface finish [4] before implantation. After the polishing, the bulk W samples were annealed in vacuum at $1200 \mathrm{~K}$ for 2 hours to desorb trapped gases.

All samples were exposed to $\mathrm{N}$ or $\mathrm{D}$ plasma in a low-pressure steady-state electron cyclotron resonance (ECR) plasma chamber 'PlaQ' which is described in Ref. [5]. Briefly, an ECR plasma was produced in a mesh-confined cage and guided through an aperture in the solid bottom plate to the sample by an external magnetic field. Between the aperture and the sample, there is a shutter which allows a burn-in time of the plasma without the sample being exposed to the beam. The ion energy of the impinging ions was controlled by applying a dc bias voltage of $-200 \mathrm{~V}$ in all implantations. Nitrogen plasma exposure was performed with a working pressure of $0.25 \mathrm{~Pa}$ applying a gas flow of $50 \mathrm{sccm} \mathrm{N}_{2}$ gas. For these conditions it was shown that $\mathrm{N}_{2}{ }^{+}$is the dominant ion species [6,7]. It contributes about $85 \%$ to the total ion flux with minor contributions from $\mathrm{N}_{3}{ }^{+}$and $\mathrm{N}^{+}$ions $(\approx 5-10 \%$ each) [7]. The ion flux of the main species was about $4 \times 10^{18} \mathrm{~N}_{2}{ }^{+} / \mathrm{m}^{2} \mathrm{~s}$ [7], which resulted in a total $\mathrm{N}$ fluence of about $1.5 \times 10^{22} \mathrm{~N} / \mathrm{m}^{2}$ for $30 \mathrm{~min}$ plasma exposure. Deuterium plasma was generated at 1.0 Pa pressure with a gas flow of $50 \mathrm{sccm}$ $\mathrm{D}_{2}$ gas. The $\mathrm{D}$ plasma consists dominantly of $\mathrm{D}_{3}{ }^{+}$ions (94\% of the deuterons) with minor contributions of $\mathrm{D}_{2}{ }^{+}(2 \%)$ and $\mathrm{D}^{+}(1 \%)$ [5]. For all samples, a D fluence of $1.0 \times 10^{24} \mathrm{D} / \mathrm{m}^{2}$ was applied. The $-200 \mathrm{~V}$ dc bias voltage together with the plasma potential of about $15 \mathrm{eV}$ [5] resulted in an energy of about $72 \mathrm{eV} / \mathrm{D}$ and $108 \mathrm{eV} / \mathrm{N}$ particle energy of the dominant ion species, respectively. On the other hand, the ion with the highest energy was in each case the small fraction of atomic ions $\left(\mathrm{D}^{+}\right.$or $\mathrm{N}^{+}$) impinging with the full energy of $215 \mathrm{eV}$. After implantation surface modifications were analyzed by optical differential interference contrast (DIC) microscopy (Olympus LEXT OLS4000).

The amounts of retained $\mathrm{N}$ and $\mathrm{D}$ in the samples were measured by nuclear reaction analysis (NRA). For D analysis the ${ }^{2} \mathrm{D}\left({ }^{3} \mathrm{He}, \mathrm{p}_{0}\right) \alpha$ nuclear reaction [9] and for $\mathrm{N}$ analysis the ${ }^{14} \mathrm{~N}\left({ }^{4} \mathrm{He}\right.$, $\left.\mathrm{p}_{0}\right){ }^{17} \mathrm{O}$ reaction [10] were used. The $\mathrm{D}$ concentration within the near-surface layer (at depth up to about $0.3 \mu \mathrm{m}$ ) was determined at a ${ }^{3} \mathrm{He}^{+}$energy of $0.69 \mathrm{MeV}$ by analyzing the emitted $\alpha$ particles with a surface barrier detector at the laboratory scattering angle of $102^{\circ}$ equipped with a 
rectangular slit reducing the solid angle to 9.16 msr. For determination of D concentration depth profiles the energy of the impinging ${ }^{3} \mathrm{He}^{+}$ions was varied. The following ion beam energies were used in the analysis of the bulk W samples: 0.69, 1.2, 1.8, 2.4, 3.2 and 4.5 MeV. A charge of $10 \mu \mathrm{C}$ was usually accumulated for each NRA spectrum. The largest analysis depth corresponding to the highest ${ }^{3} \mathrm{He}^{+}$ion energy is $7.9 \mu \mathrm{m}$. In order to determine the $\mathrm{D}$ concentration profiles SIMNRA [11] and NRADC [12] were used for the deconvolution of the NRA spectra. For $\mathrm{N}$ content measurement a ${ }^{4} \mathrm{He}^{2+}$ ion beam with energy of $4.8 \mathrm{MeV}$ was used [7]. Note that the $\mathrm{N}$ amount of the samples with sequential $\mathrm{N}$ and $\mathrm{D}$ implantation was obtained from separate samples which were implanted with $\mathrm{N}$ plasma only but under identical experimental conditions and then removed from the system for analysis. More details of ion beam analysis can be found elsewhere [13].

\section{Results and discussion}

\section{$3.1 N$ content}

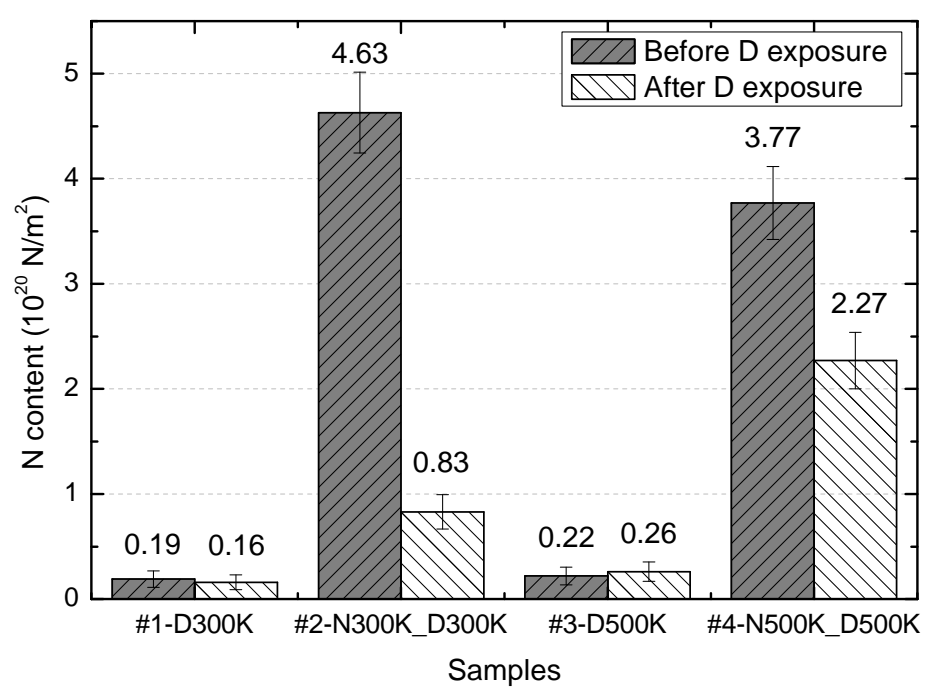

Figure 1: $N$ contents in the surface: with and without $N$ pre-implantation at $300 \mathrm{~K}$ and $500 \mathrm{~K}$.

Due to the negligible diffusivity of $\mathrm{N}$ in $\mathrm{W}$ [14], the retained amount of $\mathrm{N}$ on the $\mathrm{W}$ surface quickly saturates with fluence [7]. We assume that for our experimental conditions saturation of the $\mathrm{N}$ content is achieved. Fig. 1 shows the $\mathrm{N}$ content in the surface of the samples before and after D implantation. As one can see in the figure, even without $\mathrm{N}$ implantation (samples \#1 and \#3) the analysis always yields some counts within the relevant energy range from the ${ }^{14} \mathrm{~N}\left({ }^{4} \mathrm{He}, \mathrm{p}_{0}\right){ }^{17} \mathrm{O}$ nuclear reaction. We assume that these few counts are due to adsorbents stemming from the transport of the samples through air and cannot be avoided. The corresponding samples (\#1 and \#3) after D plasma exposure also show a comparable $\mathrm{N}$ content as prior to D plasma exposure. This supports, on the one hand, the interpretation that this $\mathrm{N}$ signal is due to transport through air, and shows, on the other hand, that during $\mathrm{D}$ plasma 
exposure no nitrogen impurities are accumulated in the sample. After 30 min of $\mathrm{N}$ implantation at $300 \mathrm{~K}$ (sample \#2), the $\mathrm{N}$ content in the $\mathrm{W}$ surface increases significantly from a background level of $\sim 0.2 \times 10^{20} \mathrm{~N} / \mathrm{m}^{2}$ to $\sim 4.6 \times 10^{20} \mathrm{~N} / \mathrm{m}^{2}$. At $500 \mathrm{~K}$, the $\mathrm{N}$ content increases from a similar background level to $\sim 3.8 \times 10^{20} \mathrm{~N} / \mathrm{m}^{2}$, which is about $25 \%$ lower than that at $300 \mathrm{~K}$. This might be due to a different phase of $\mathrm{WNx}$ forming at the higher temperature, which is also reported in [7]. After D plasma exposure the $\mathrm{N}$ contents are substantially reduced, but they are still significantly higher than the background levels found for samples \#1 and \#3. Surprisingly, the retained $\mathrm{N}$ content in samples after $\mathrm{D}$ exposure at $500 \mathrm{~K}$ is much higher than that at $300 \mathrm{~K}$, even though the initial $\mathrm{N}$ amount is lower. This means that at $500 \mathrm{~K}$, the $\mathrm{N}$ loss after the same $\mathrm{D}$ fluence is much lower than that at $300 \mathrm{~K}$. From this observation we conclude that the interaction of D plasma with the W-N surface is distinctly different at different temperatures.

\subsection{Surface modification}
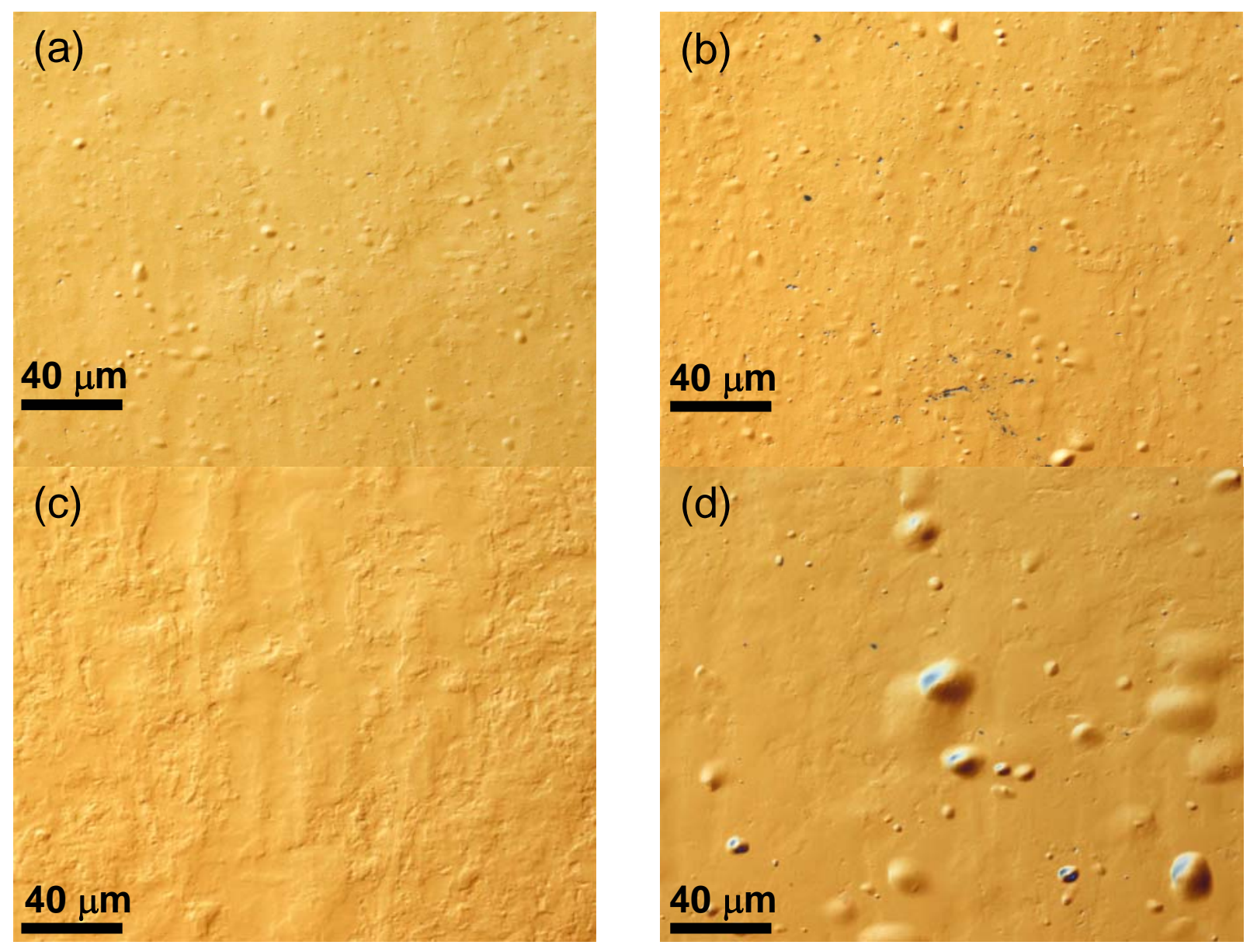

Figure 2: Optical DIC micrographs of blisters on stress-relieved tungsten with or without $N$ preimplantations during implantation at $72 \mathrm{eV} / \mathrm{D}$ to a fluence of $1 \times 1024 \mathrm{D} / \mathrm{m} 2$ at different temperatures: (a) \#1-D300 K, (b) \#2-N300 K_D300 K, (c) \#3-D500 K and (d) \#4-N500 K_D500 K. 
Under appropriate exposure conditions tungsten can be oversaturated with deuterium [8, 15] leading to the formation of gas-filled bubbles in the bulk. As a special case, so-called blisters can be formed at the surface $[8,15]$. It has been reported frequently that blisters in W vary considerably in terms of their size, shape and abundance depending on exact exposure conditions, such as temperatures, fluence, bias voltage [8] and simultaneously impinging impurity flux [16, 17]. Fig. 2 shows the surface morphology of the samples exposed to the same D implantation (72 eV per $\mathrm{D}$ atom, fluence $1.0 \times 10^{24} \mathrm{D} / \mathrm{m}^{2}$ ) but after different $\mathrm{N}$ pre-treatments. The surfaces before implantation are not shown here because all samples were polished using the same procedures. The surfaces prior to D implantation are comparable to Fig. 2c. Plasma exposure at $300 \mathrm{~K}$ causes the appearance of blisters with diameters of 2-9 $\mu \mathrm{m}$ (Figs. 2a and b), no matter whether the sample was pre-implanted with $\mathrm{N}$ or not. It seems that the $\mathrm{N}$ pre-implantation at $300 \mathrm{~K}$ does not distinctly affect blistering of the sample. But for samples exposed at $500 \mathrm{~K}, \mathrm{~N}$ pre-implantation noticeably influences blistering: With $\mathrm{N}$ pre-implantation many large blisters with diameters up to $\sim 40 \mu \mathrm{m}$ are found on the surface while without $\mathrm{N}$ pre-implantation, one can hardly find a blister on the surface of the specimen. Actually, we have scanned the whole sample surface and did not find any blister on it.

As mentioned above, many factors, especially the temperature, influence the blistering behavior. It is not easy to interpret the absence of blistering on the not $\mathrm{N}$-implanted $\mathrm{W}$ sample after $\mathrm{D}$ loading at $500 \mathrm{~K}$, since no comparable experimental conditions (ion energy, temperature and fluence) can be found in literature. It was reported that the critical temperature for blister suppression is $700 \mathrm{~K}$ [18], however, the ion flux in that work was much higher than the present one. A corresponding check of this issue is planned for the future. From the literature it is known that the diffusivity of D in W increases with temperature [19] while the concentration of trapped $\mathrm{D}$ in $\mathrm{W}$ decreases with increasing temperature [8]. Both processes may suppress the formation of blisters. The observation that with $\mathrm{N}$ pre-implantation at $500 \mathrm{~K}$ much larger blisters occur indicates that the $\mathrm{W}-\mathrm{N}$ layer formed by $\mathrm{N}$ pre-implantation can enhance the $\mathrm{D}$ concentration in the bulk for the same accumulated fluence.

\section{3 $\mathrm{D}$ depth distribution}

Fig. 3 shows the $\mathrm{D}$ depth distribution in the sample, in which the deuterium concentration deduced by NRADC is plotted as function of depth with the $\mathrm{W}$ areal density as unit (bottom axis). Additionally, the corresponding thickness in micrometers (using the mass density of bulk $\mathrm{W}$ ) is plotted on the top axis. The two samples with plasma exposure at $300 \mathrm{~K}$ (\#1 and \#2) show almost identical deuterium depth profiles. For both a very thin near-surface layer (about $16 \mathrm{~nm}$ thick) with $\sim 3.9 \%$ deuterium concentration is found. Note that the $16 \mathrm{~nm}$ thickness of this Drich layer is determined by the depth resolution of the $\alpha$ spectrum measured at $0.69 \mathrm{MeV}$. Correspondingly, the given $\mathrm{D}$ concentration is the mean value in this layer. Beyond this D-rich layer the $\mathrm{D}$ concentration decreases monotonically from about $2 \times 10^{-3}$ to $3-4 \times 10^{-5}$ in depths larger than about $4 \mu \mathrm{m}$. The $\mathrm{D}$ depth profiles for the two samples exposed at $500 \mathrm{~K}$ (\#3 and \#4) are largely different from each other and from the $300 \mathrm{~K}$ profiles. The sample without $\mathrm{N}$ preimplantation has a much lower D surface concentration (about $1.6 \%$ ) than the N pre-implanted sample, which has a concentration comparable to the two samples implanted at $300 \mathrm{~K}$. The two $500 \mathrm{~K}$ samples also exhibit very different D profiles in the subsurface region. Without $\mathrm{N}$ preimplantation, we measure a constant $\mathrm{D}$ concentration of about $0.01 \%$ extending throughout the remaining accessible $\mathrm{W}$ depth. In contrast, the $\mathrm{N}$ pre-implanted sample shows a steep decrease 
from $4.5 \%$ to $\sim 0.024 \%$ followed by a second maximum. At a depth of about 3 to $5 \mu \mathrm{m}$, the D concentration increases to a level about eight times higher than the concentration at the corresponding depth of the sample without $\mathrm{N}$ pre-implantation. Beyond this depth the $\mathrm{D}$ concentration in the N-pre-implanted sample is still 40 to $50 \%$ higher.

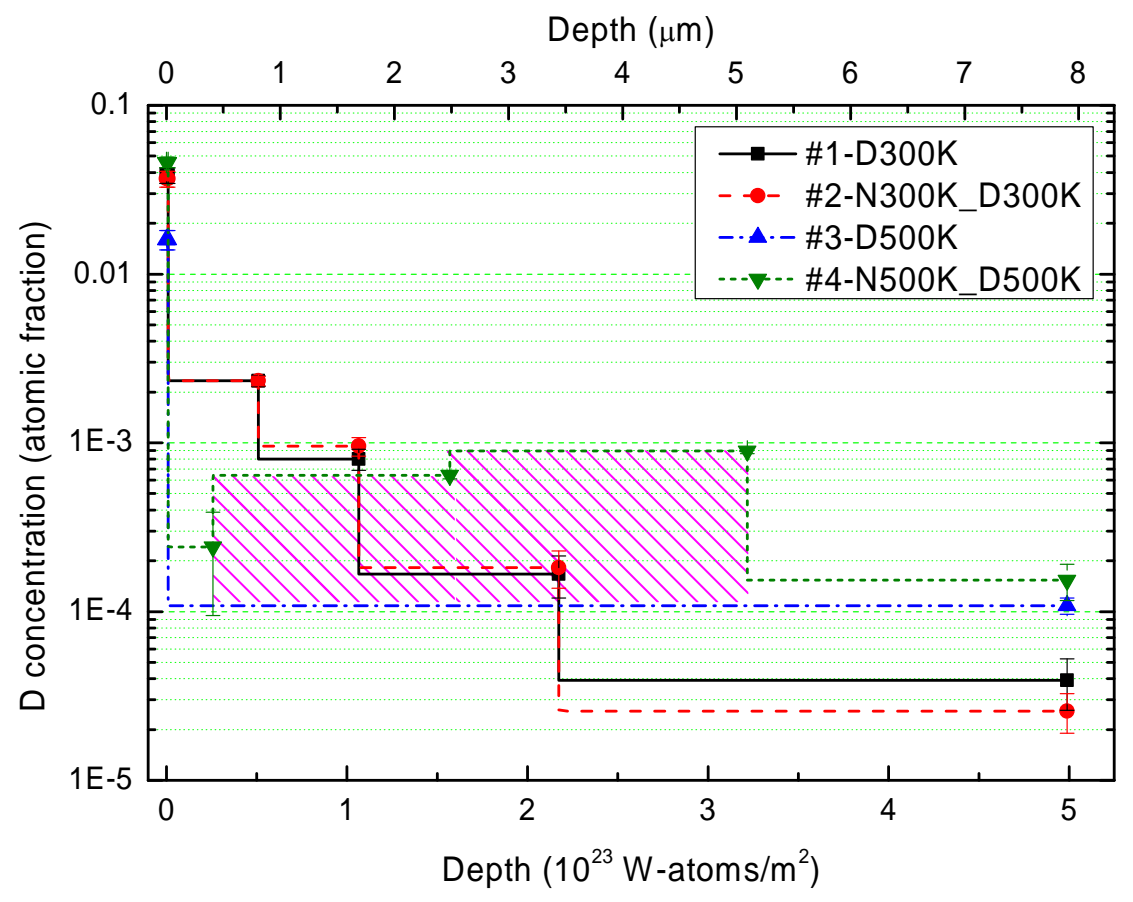

Figure 3: Deuterium depth profiles in stress-relieved tungsten with or without $N$ pre-implantation after deuterium implantation with $72 \mathrm{eV} / \mathrm{D}$ to a fluence of $1 \times 1024 \mathrm{D} / \mathrm{m} 2$ at different temperatures (same specimens as shown in Figs. 1 and 2). The bottom $x$-axis scale shows thickness in $W$ atoms $/ \mathrm{m} 2$ and the top axis in micrometers.

Fig. 3 clearly shows that at $300 \mathrm{~K}$, the $\mathrm{N}$ pre-implantation has no detectable influence on the D depth distribution while it has a significant effect at $500 \mathrm{~K}$. This observation is actually in agreement with the conclusions drawn from the observed blistering behavior (see Sect. 3.2). Comparing the $\mathrm{D}$ concentration in the surface layer we find that the sample implanted at $500 \mathrm{~K}$ with D only has the lowest surface D concentration among the four samples. This is explained as follows: The surface concentration is dominated by the defect density in the surface. At the bias voltage used in the present experiments $(-200 \mathrm{~V})$ defects can be generated by impinging $\mathrm{N}$ ions but not by $\mathrm{D}$ ions. As a result, for samples with $\mathrm{N}$ pre-implantation the density of trap sites in the surface may be higher than for the samples without $\mathrm{N}$ pre-implantation. On the other hand, at higher temperature the trap sites are only partially filled due to thermal detrapping such that for the case without $\mathrm{N}$ pre-implantation the surface concentration is lower.

The samples exposed at $500 \mathrm{~K}$ exhibit a higher D concentration in larger depth (beyond a depth of $\sim 3.5 \mu \mathrm{m}$; please observe that the thickness scale is shown on the top axis) than the samples exposed at $300 \mathrm{~K}$. This is due to the higher D diffusivity at $500 \mathrm{~K}$. In addition, at $500 \mathrm{~K}$ the $\mathrm{N}$ pre-implanted sample has in the range from 0.5 to $5 \mu \mathrm{m}$ a much higher concentration than the 
sample without $\mathrm{N}$ pre-implantation. This indicates that the $\mathrm{N}$-containing layer formed by $\mathrm{N}$ preimplantation can at this temperature significantly enhance the $\mathrm{D}$ concentration in the bulk and particularly in this depth region. Note that, due to the negligible diffusivity of $\mathrm{N}$ in $\mathrm{W}$ at temperatures lower than $600 \mathrm{~K}$ [7] $\mathrm{N}$ pre-implantation can only affect a very narrow region corresponding to the ion penetration depth of about $1.5 \mathrm{~nm}$ and cannot create defects in the bulk beyond this depth. It is, therefore, reasonable to assume that the initial defect densities in the bulk of the two samples are the same, as it is also indicated by the similarity of the D concentration beyond $5 \mu \mathrm{m}$. If no new trap sites are created in the bulk during $\mathrm{N}$ implantation, the retained D amount in the bulk should be similar for both samples (\#3 and \#4) because they have experienced the same $\mathrm{D}$ plasma exposure conditions (temperature, bias voltage and fluence). We, therefore, conclude that the measured higher $\mathrm{D}$ concentration between 0.5 and $5 \mu \mathrm{m}$ for the sample with $\mathrm{N}$ pre-implantation is closely related to the appearance of blisters. Based on the presently available data it cannot be finally decided whether the blisters are the cause or the consequence of the increased D concentration. However, the localization of the enhanced D concentration in the range between 1 and $5 \mu \mathrm{m}$ favors the conclusion that blisters are the cause. Typically blisters due to $\mathrm{D}$ implantation into $\mathrm{W}$ occur in this depth range $[8,15,20]$. It was recently suggested that blisters do not only retain $\mathrm{D}$ in form of molecules inside the cavity, but also $\mathrm{D}$ atoms in trap sites in the surrounding of the blisters which are created by plastic deformation of the W lattice [8].

One can roughly estimate the total retained $\mathrm{D}$ amount due to the presence of $\mathrm{N}$ in the near surface region from the hatched area in Fig. 3. Beyond about $5 \mu \mathrm{m}$ up to the limit of the NRA probing depth the $\mathrm{D}$ concentration in the samples at $500 \mathrm{~K}$ is $4-5$ times higher than that at $300 \mathrm{~K}$. This is attributed to the higher diffusivity of $\mathrm{D}$ at elevated temperature. According to diffusiontrapping models $[8,19]$ more $\mathrm{D}$ can diffuse to larger depth and fill the trap sites there. This results in a higher $\mathrm{D}$ concentration in larger depth. In contrast, at higher temperature detrapping is enhanced leading to a lower occupation of the available traps. The observation that at $500 \mathrm{~K}$ the local $\mathrm{D}$ concentration in depths larger than $4 \mu \mathrm{m}$ is higher than at $300 \mathrm{~K}$ indicates that at $300 \mathrm{~K}$ the traps in this depth range are not yet filled because diffusion is not high enough to enable filling at the fluence used.

Fig. 4 shows the total retained D amount within the NRA probing depth. Compared with the incoming $\mathrm{D}$ amount, the retained $\mathrm{D}$ amount in each of the four samples is very low (less than $0.1 \%$ ), which is in agreement with the fact that $\mathrm{D}$ retention in $\mathrm{W}$ is very low and leads to a very small concentration (0.01-0.03 \%) [8]. Both samples treated at $300 \mathrm{~K}$ show almost identical total retained $\mathrm{D}$ amounts of about $2.3 \times 10^{20} \mathrm{D} / \mathrm{m}^{2}$. At $500 \mathrm{~K}$, the total amount without $\mathrm{N}$ preimplantation decreases to about $0.7 \times 10^{20} \mathrm{D} / \mathrm{m}^{2}$ while for the sample with $\mathrm{N}$ pre-implantation it increases to $3.1 \times 10^{20} \mathrm{D} / \mathrm{m}^{2}$. That means, at $500 \mathrm{~K}$ the retained amount with $\mathrm{N}$ pre-implantation is not only a factor of 4 higher than without $\mathrm{N}$ pre-implantation, but also about $50 \%$ higher than at $300 \mathrm{~K}$.

As mentioned above, one can evaluate the additional $\mathrm{D}$ retention due to the presence of the $\mathrm{N}$ containing surface layer by calculating the $\mathrm{D}$ amount of the hatched area between the depth profiles of sample \#3 and \#4 (in depth range from $0.5 \mu \mathrm{m}$ to $5 \mu \mathrm{m}$ ) in Fig. 3. As discussed above, we attribute this additional retention dominantly to the presence of blisters and the corresponding additional trapping sites in the surrounding $\mathrm{W}$ lattice. It turns out that a large part of the retained $\mathrm{D}$ in $\mathrm{W}(68 \%)$ with $\mathrm{N}$ pre-implantation at $500 \mathrm{~K}$ is related to blistering in the sample. This 
contribution is indicated in Fig. 4 by the differently hatched lower part of the corresponding column.

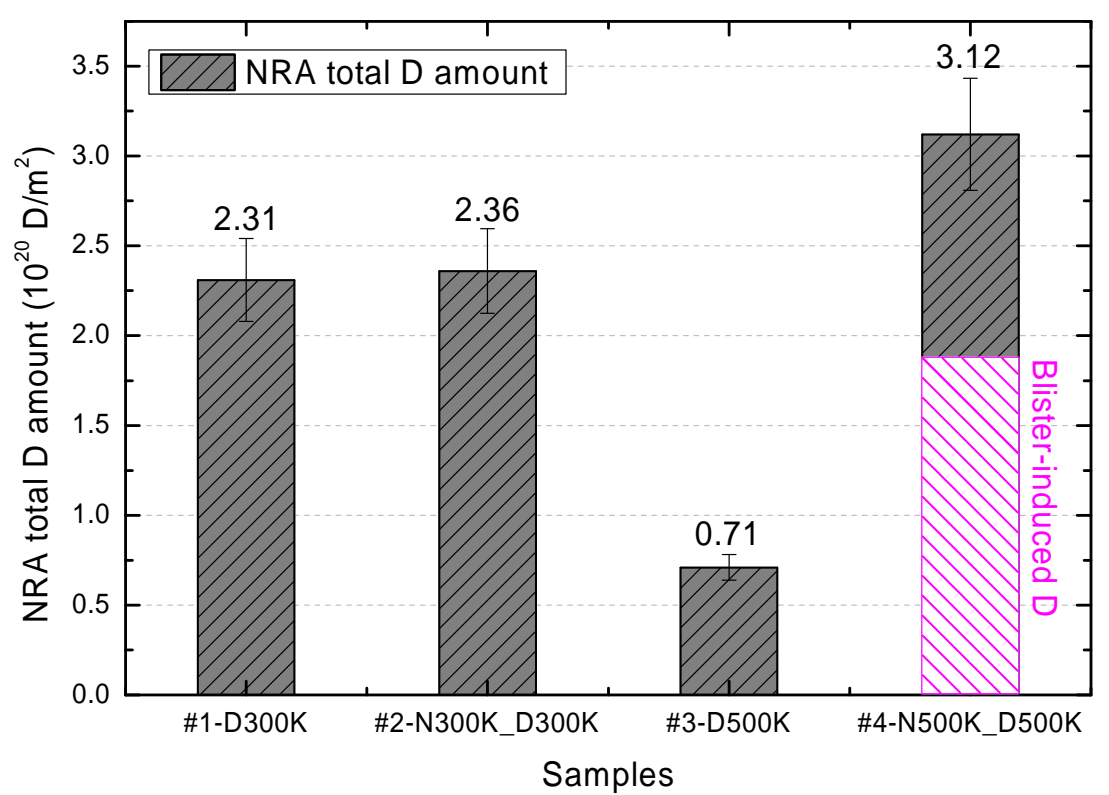

Figure 4: Total amount of retained deuterium within the NRA-probing depth.

\subsection{Discussion}

From what has been shown above, it is clear that the N-containing layers formed by $\mathrm{N}$ preimplantation play at different temperatures quite different roles on the $\mathrm{D}$ retention during the following $\mathrm{D}$ implantation. On the one hand, the $\mathrm{N}$-containing layers themselves are different after $\mathrm{N}$ pre-implantation at different temperature because we find different initial $\mathrm{N}$ contents after the same $\mathrm{N}$-implantation fluence and also very different removal behavior of these layers after the same D-implantation fluence. This may influence the subsequent $\mathrm{D}$ retention. On the other hand, the microscopic processes, such as diffusion, trapping, and surface recombination and desorption are strongly temperature dependent and may contribute differently at different temperatures [21,22].

As described in Sec. 2, the ion flux from the nitrogen plasma consists dominantly of $\mathrm{N}_{2}{ }^{+}$but also some $\mathrm{N}^{+}$ions (about $5 \%$ of the ions) impinge on the sample. Similarly, the ion flux from our deuterium contains some $\mathrm{D}^{+}$ions (about $1 \%$ of the deuterons). These atomic ions have the maximum impact energy and, therefore, also the highest penetration depth. At the bias voltage of $-200 \mathrm{~V}$ (resulting in an ion energy of $215 \mathrm{eV}$ ) used here the maximum penetration depth for $\mathrm{D}^{+}$ ions is about $6.3 \mathrm{~nm}$ and $1.6 \mathrm{~nm}$ for $\mathrm{N}^{+}$[23]. Even for the dominant $\mathrm{D}_{3}{ }^{+}$ion with an energy of $72 \mathrm{eV}$ per deuteron the $\mathrm{D}$ penetration depth is about $2.0 \mathrm{~nm}$ larger than that for $\mathrm{N}^{+}$. This means that essentially all impinging $\mathrm{D}$ ions can penetrate deeper than $\mathrm{N}$ ions. Note that the penetration depth values are calculated for pure tungsten. They might be slightly different for N-containing tungsten layers. At the different temperatures used, the $\mathrm{W}$-N layer should have a similar influence on the penetration of impinging $\mathrm{D}$ particles. However, after being implanted into $\mathrm{W}$ 
beyond this $\mathrm{W}-\mathrm{N}$ layer, all the thermalized $\mathrm{D}$ atoms should show comparable diffusion behavior in the W bulk, which is determined by the sample temperature. At $300 \mathrm{~K}$ we observe that the $\mathrm{W}$ $\mathrm{N}$ layer has no significant influence on the D retention. Neither the total amounts (Fig. 4) nor the depth profiles (Fig. 3) differ significantly. At $300 \mathrm{~K}$ the total initial $\mathrm{N}$ amount in the W-N layer is higher than at $500 \mathrm{~K}$ but the remaining amount of $\mathrm{N}$ after D plasma exposure (Fig. 1) is much lower. From these observations we conclude that, on the one hand, the W-N layers formed at 300 and $500 \mathrm{~K}$ are different, and, on the other hand, that their influence on D retention at these temperatures is also very different. It appears that the $\mathrm{W}-\mathrm{N}$ layer formed at $500 \mathrm{~K}$ either acts as a rather efficient diffusion barrier for $\mathrm{D}$ or significantly reduces the recombination coefficient of $\mathrm{D}$ at the surface while at $300 \mathrm{~K}$ it doesn't. Each of these explanations is presently possible and each would lead to a higher retention of D.

\section{Conclusion}

A set of bulk W samples was implanted with $\mathrm{D}$ up to a fluence of $1 \times 10^{24} \mathrm{D} / \mathrm{m}^{2}$ with or without $\mathrm{N}$ pre-implantation at $300 \mathrm{~K}$ and $500 \mathrm{~K}$. The surface modification by blistering as well as the $\mathrm{D}$ depth distribution measured by NRA show that $\mathrm{N}$ pre-implantation plays a very different role for $\mathrm{D}$ retention in the following D plasma exposure at the different applied temperatures: At $500 \mathrm{~K}$, the W-N layer strongly enhances D retention; while at $300 \mathrm{~K}$ it has no obvious effect.

\section{Acknowledgements}

The stay of L. Gao at Max-Planck Institute for Plasma Physics in Garching (IPP) was funded through a Joint Doctoral Promotion Programme between Max-Planck Society (MPG) and the Chinese Academy of Sciences (CAS), which is gratefully acknowledged. The stay of P. Wang at IPP was funded through a bilateral agreement between MPG and CAS which is also gratefully acknowledged. Intense discussions with Dr. Martin Balden on the interpretation of experimental results are highly appreciated. Thanks are further due to Michael Fußeder and Joachim Dorner for help with the NRA measurements. 


\section{References}

[1] Kallenbach A., Bernert M., Eich T. et al. 2012 Nucl. Fusion 52122003

[2] Schweinzer J., Sips A. C. C., Tardini G. et al. 2011 Nucl. Fusion 51113003

[3] Kallenbach A., Dux R., Mayer M. et al. 2009 Nucl. Fusion 49045007

[4] Manhard A., Matern G. and Balden M. 2013 Practical Metallography 2013/01, 5-16

[5] Manhard A., Schwarz-Selinger T. and Jacob W. 2011 Plasma Sources Sci. T. 20015010 Note: Unfortunately, the information given in the last paragraph of this article is not correct, but the information in figures 5 and 6 is correct. The contribution of the molecular ions to the total ion flux for standard conditions is: $\mathrm{D}_{3}{ }^{+}=94 \%, \mathrm{D}_{2}{ }^{+}=3 \%$ and $\mathrm{D}^{+}=3 \%$. Correspondingly, the contributions to the total deuteron flux in form of ions are: $97 \%, 2 \%$, and $1 \%$.

[6] Wang Y. and Olthoff J. K. 1999 J. Appl. Phys. 856358

[7] Schmid K., Manhard A., Linsmeier C. et al. 2010 Nucl. Fusion 50025006

[8] Manhard A. 2012 Max-Planck-Institut für Plasmaphysik (Garching), IPP Report 17/34, PhD thesis, Univ. Augsburg

[9] Alimov V. K., Mayer M. and Roth J. 2005 Nucl. Instr. Meth. Phys. B 234169

[10] Giorginis G., Misaelides P., Crametz A. et al. 1996 Nucl. Instr. Meth. Phys. B 113396

[11] Mayer M. 1997 Max-Planck-Institut für Plasmaphysik (Garching), IPP Report 9/113

[12] Schmid K. and von Toussaint U. 2012 Nucl. Instr. Meth. Phys. B 28164

[13] Mayer M. 2002 Nucl. Instr. Meth. Phys. B 194177

[14] Keinonen J., Räisänen J. and Anttila A. 1984 Appl. Phys. A-mater. 35227

[15] Manhard A., Schmid K., Balden M. et al. 2011 J. Nucl. Mater. 415 S632

[16] Ueda Y., Shimada T. and Nishikawa M. 2004 Nucl. Fusion 4462

[17] Ogorodnikova O. V., Sugiyama K., Markin A. et al. 2011 Phys. Scripta. 2011014034

[18] Alimov V. K., Roth J., Causey R. A. et al. 2008 J. Nucl. Mater. 375192

[19] Frauenfelder R. 1969 J. Vac. Sci. Technol. 6388

[20] Lindig S., Balden M., Alimov V. K. et al. 2011 Phys. Scripta. 2011 T145 014039

[21] Krom A. M. and Bakker A. 2000 Metallurgical and Materials Transactions B 311475

[22] Causey R. A. 2002 J. Nucl. Mater. 30091

[23] Eckstein W. 2011 Max-Planck-Institut für Plasmaphysik (Garching), IPP Report 17/29 